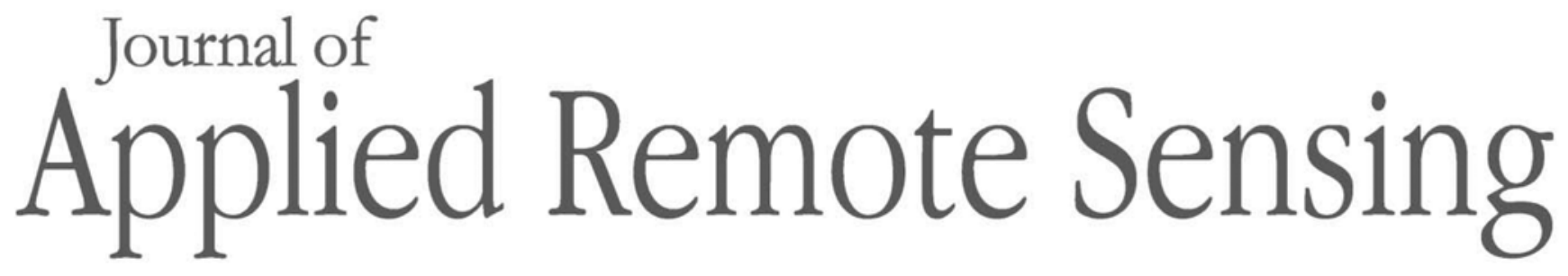

RemoteSensing.SPIEDigitalLibrary.org

\title{
Temperature monitoring along the Rhine River based on airborne thermal infrared remote sensing: estimation of in situ water temperatures and inflow detection compared to artificial satellite data
}

Katharina Fricke

Björn Baschek

\section{SPIE.}




\title{
Temperature monitoring along the Rhine River based on airborne thermal infrared remote sensing: estimation of in situ water temperatures and inflow detection compared to artificial satellite data
}

\author{
Katharina Fricke* and Björn Baschek \\ Federal Institute of Hydrology, Department of Geo-Information and Remote Sensing, \\ GRDC, Am Mainzer Tor 1, 56068 Koblenz, Germany
}

\begin{abstract}
Water temperature is an important parameter of water quality. It influences the survival and growth of animal and plant species in river ecosystems. Current in situ measurements do not allow for the spatial coverage that is necessary for continuous monitoring. Hence, the ability of remote sensing temperatures from aerial and artificial satellite datasets to accurately identify and investigate water temperature and inflows is evaluated for a case study of the Upper and Middle Rhine River. Water surface temperatures acquired by an aerial survey and the results of two correction methods were evaluated: the difference to in situ measurements could be reduced to $0.04 \pm 0.21^{\circ} \mathrm{C}$ with a calibration based on in situ measurements and to $0.14 \pm$ $0.33^{\circ} \mathrm{C}$ based on atmospheric parameters modeled with MODTRAN ${ }^{\circledR}$ 5.3.2. Inflows and mixing processes of water bodies with differing temperatures could be identified successfully with the change point analysis method and based on the standard deviation of the distributed longitudinal profile even for smaller dischargers. With the artificial satellite datasets, the ability to detect inflows decreases mainly with the noise of the dataset, also leading to a higher number of false positive change points. () The Authors. Published by SPIE under a Creative Commons Attribution 3.0 Unported License. Distribution or reproduction of this work in whole or in part requires full attribution of the original publication, including its DOI. [DOI: 10.1117/1.JRS.9.095067]
\end{abstract}

Keywords: thermal infrared; surface water temperature; longitudinal river temperature profile; Landsat ETM+; MODTRAN; inflow detection.

Paper 15096P received Feb. 4, 2015; accepted for publication Jun. 11, 2015; published online Jul. 22, 2015.

\section{Introduction}

In a river ecosystem, water temperature is an important parameter for water quality ${ }^{1}$ and influences the growth and decline of species living in and near the aquatic habitat. ${ }^{2}$ At most rivers, the water temperature is measured at water quality measurement stations which are widespread along the river course. Water discharges with differing temperatures in between measurement stations may go unnoticed as they mix with the river water before the measurement station is reached and the original temperature difference is somewhat diminished. In other cases, the measurement station does not capture the temperature difference as its location is inappropriate for this task. To monitor the water temperature and discharges along the river, additional, spatially distributed data are necessary.

Thermal infrared (TIR) remote sensing is an established method for the retrieval of sea surface temperatures. ${ }^{3,4}$ TIR data from satellite sensors have also been used for the investigation of inland water bodies, e.g., time series and longitudinal profiles of stream temperatures, ${ }^{5-7}$ thermal water pollution and river plumes in estuaries and lagoons, ${ }^{8,9}$ lake surface temperatures, ${ }^{10}$ and groundwater inflow and thermal anomalies. ${ }^{11}$ For smaller water bodies, the resolution of satellite sensors may be insufficient and airborne thermal remote sensing is necessary to observe the desired processes. Applications of airborne TIR remote sensing include investigating the stream temperature variation ${ }^{12}$ and fine-scale thermal features such as tributaries and groundwater

*Address all correspondence to: Katharina Fricke, E-mail: fricke@bafg.de 
inputs, ${ }^{13}$ quantification of groundwater discharge and its detailed spatial patterns, ${ }^{14}$ assessing stream temperatures affected by land use, ${ }^{15}$ and thermal heterogeneity of floodplains related to fish distributions. ${ }^{16,17}$

The aim of this paper is to test the applicability of TIR for the investigation of river water temperatures and the effects of dischargers in German waterways. Spatially distributed temperature data for inland waterways in Germany can be provided by satellite imagery acquired in the TIR wavelength region of a sufficient spatial resolution (e.g., Landsat 5, 7, and 8; ASTER), but also by aerial surveys. Both data sources have their own advantages, specifically the low cost of the satellite data and the high spatial resolution and flexibility of the aerial survey. The spatial resolution often decides whether the dataset can be used for inland waterways, helping to detect inflows and to identify the temperature difference between the inflowing and the river water. The accuracy and applicability of TIR remote sensing to observe spatial patterns with different resolutions has also been assessed by several studies. ${ }^{18-20}$ At least three pixels over water across the stream are necessary to resolve the river water surface temperature. ${ }^{18}$ In this paper, we will first evaluate the ability of airborne TIR data acquired over the Rhine River to predict water bulk temperatures by comparing the original and corrected water surface temperatures from the survey to in situ measurements. Bulk temperature, not the skin temperature acquired by remote sensing, is the interesting indicator for water quality and ecological models. Second, we used the change point analysis and standard deviation of the temperature across the river to detect inflows with different water temperatures and evaluate mixing processes along the longitudinal river profile of the Rhine River. These methods were tested with the original aerial survey and artificial satellite datasets similar to Landsat data to evaluate the effects of spatial resolution and noise on the detection method.

\section{Research Area}

For this study, the research area is the Rhine River from Rhine kilometer (Rh-km) 334 in Iffezheim to Rh-km 571.2 in Boppard (see Fig. 1). The river stretch includes part of the
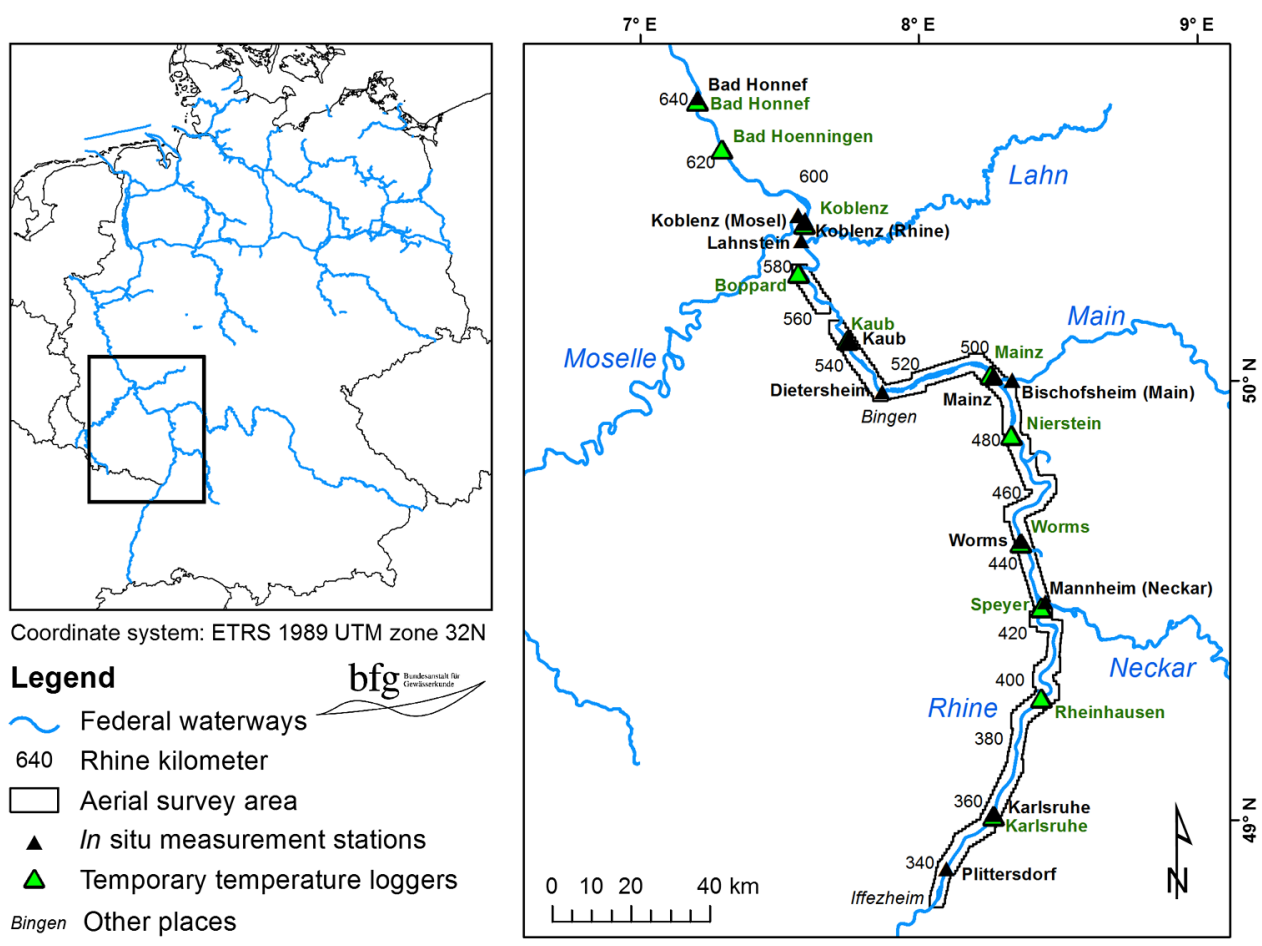

Fig. 1 The research area along the Rhine River from Iffezheim (Rh-km 334) to Boppard (Rh-km 571.2) with the location of major tributaries, water quality measurement stations, and temperature data loggers (data sources: BfG, Federal Ministry for the Environment, Nature Conservation, Building and Nuclear Safety, WSV, DWD). 
Upper Rhine in the Rhine Rift Valley between Iffezheim and Bingen (250 to $500 \mathrm{~m}$ river width) and the first part of the Middle Rhine Valley with a narrower river valley from Bingen to Boppard (150 to $400 \mathrm{~m}$ river width). The main tributaries in this river section are the Neckar, Main, and Nahe, but industrial enterprises, power plants, and treatment plants also discharge water into the river. In Karlsruhe and Mainz, the cooling water from power plants is the main source of anthropogenic heat discharge. ${ }^{21,22}$ Downstream of a discharge source, the inflow can form plumes for kilometers with differences in water temperatures of over $1{ }^{\circ} \mathrm{C} .{ }^{21}$ The influence of the known inflow sources on the water temperature has been modeled and shows a large effect directly at the discharge source with decreasing impact downstream. ${ }^{23}$ This alters the temperature regime in certain river areas where, for example, the shipping traffic can profit from the reduced ice drift. However, it can also enforce ecosystem changes and the local introduction of new species and the displacement of existing species compared to the regular plant and animal communities. Since the late 1970s, the mean annual water temperatures in the Rhine River have been rising, with an increase of $1.3^{\circ} \mathrm{C}$ in Mainz and $1.2^{\circ} \mathrm{C}$ in Koblenz (1978 to 2011). ${ }^{24}$ This could have been caused by climate change, ${ }^{21}$ but direct heat discharges, urbanization and changing river morphology also have an impact on the river temperature. ${ }^{1}$

\section{Data}

\subsection{Aerial Survey}

An aerial survey of the research area was conducted on October 31, 2013, between 12:30 and 3:00 p.m. UTC on behalf of the Federal Institute of Hydrology (BfG). Data of the Rhine River were acquired with two camera systems: a digital camera with RGB and near-IR channels, and a thermal imaging camera measuring the brightness temperature in the 8 to $12 \mu \mathrm{m}$ wavelength region. The thermal camera was an extended version of the Image IR 8800 by InfraTec with an mercury cadmium tellurid detector, an absolute accuracy better than $1 \%$, a relative temperature resolution, and accuracy of $0.025 \mathrm{~K}$. This camera system had a focal plane array of $640 \times 512$ pixels and a focal length of $13 \mathrm{~mm}$ and was deployed on an aircraft that flew at an altitude of $\sim 3000 \mathrm{~m}$. At the given flight altitude, the resolution of the TIR camera allowed for a ground sampling distance of $4 \mathrm{~m}$ and an orthorectified image of $\sim 2800 \mathrm{~m} \times 2150 \mathrm{~m}$ covering the whole width of the main stream and larger branches. The RGB and NIR data were acquired with the digital camera UltraCamXp by Vexcel and captured at the same time as the TIR data. Due to a higher pixel resolution, the final RGBNIR image had a spatial resolution of $0.8 \mathrm{~m}$. A classification of the RGBNIR images was performed to eliminate land or mixed pixels and the effects of land surface temperatures as well as to identify clouds and shadows present during the data acquisition. The classification was based on band indices (normalized difference vegetation index based on the NIR and the red bands, normalized difference water index based on the green and NIR bands) and thresholds, derived from training areas/ground control points in the RGBNIR dataset where the surface characteristics were known. With very strict thresholds, mixed pixels capturing a combination of land and water surfaces were identified and with the land pixels omitted from further analysis. Fortunately, no clouds were identified over the water surface.

\subsection{Satellite Data}

As mentioned in Sec. 1, river water temperatures can also be provided by satellite data. The accuracy of temperatures from Landsat ETM+ and the possibility to identify dischargers along the Rhine River has been evaluated in a previous study. ${ }^{6}$ In this paper, the capabilities of satellite data will be evaluated based on artificial satellite datasets derived from the aerial survey (see Sec. 4.3).

\subsection{Longitudinal Temperature Profiles}

To reduce the amount of data to be processed, longitudinal profiles of the river temperature were created by selecting points evenly distributed every $100 \mathrm{~m}$ along the river center line. The temperature from the aerial survey extracted at their coordinates normally represents the water temperature of the main river stream (see Fig. 2). To capture water plumes on either stream 
side, an additional point raster with $100 \mathrm{~m}$ spacing was distributed over the river and related to the closest $100 \mathrm{~m}$ profile point for a distributed longitudinal profile. Raster temperature and classification value (water, land, cloud, or shadow) were extracted for each raster point and summary statistics, such as mean and standard deviation of the water temperature, were calculated for each $100 \mathrm{~m}$ profile point.

\subsection{In Situ Measurements}

The measurements from several water quality measurement stations along the Rhine and its tributaries were used for the comparison of remote sensing temperatures with in situ temperatures (see Fig. 1). The measurement stations are listed in Table 1 with the responsible operators. The measurement stations measure the bulk water temperature at the river shore and, in some cases, also across the river (Worms and Mainz). Independent of the instrumental accuracy, the accuracy of the bulk water measurements can vary from 0.1 to $0.25^{\circ} \mathrm{C}$ up to $0.5^{\circ} \mathrm{C},{ }^{22}$ depending on the maintenance of the measurement station.

In addition to the water quality measurement stations, temperature data loggers were temporarily deployed with the support of the Federal Waterway and Shipping Administration (WSV) at lateral buoys of the river channel at a depth of $1 \mathrm{~m}$. Their locations were close to some of the regular measurement stations but were also in between to complement the density of the in situ measurement network. The absolute accuracy of the temperature data loggers was $\pm 0.1^{\circ} \mathrm{C}$ according to the manufacturer's calibration and the test calibration performed before deployment. Most temporary temperature loggers close to water quality measurement stations confirmed the station measurements within the expected accuracy limits.

\subsection{Additional Data}

For the atmospheric correction, the atmospheric conditions were derived from a combination of weather data at ground level and predefined standard atmospheric profiles from the atmospheric

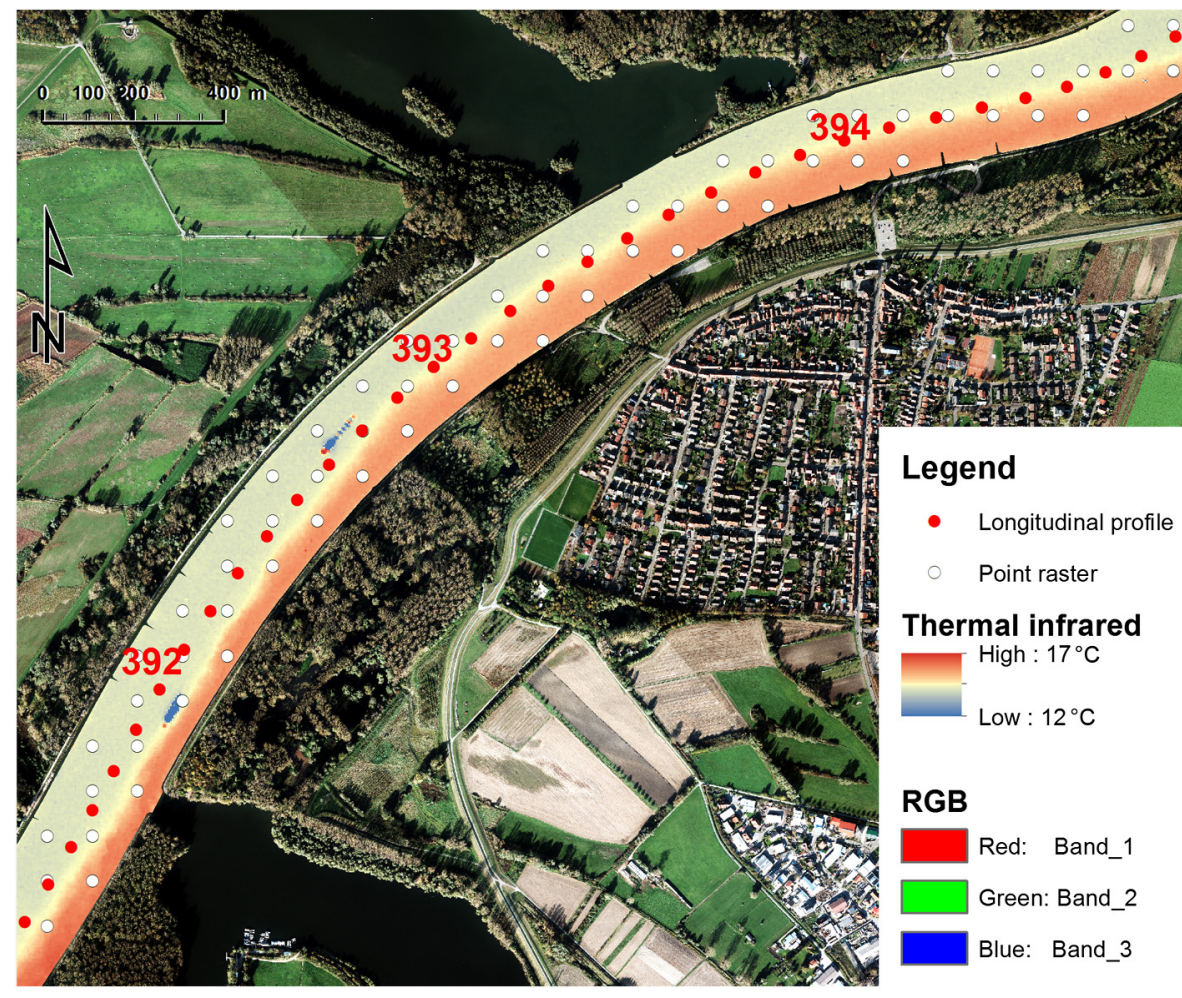

Fig. 2 Example of the RGBNIR (land) and thermal infrared data (water area) from the aerial survey as well as the longitudinal profile with $100 \mathrm{~m}$ intervals and the distributed longitudinal profile with $100 \mathrm{~m}$ spacing (data source: $\mathrm{BfG}$ ). 
Table 1 Water quality stations and temperature data loggers along the Rhine and its tributaries (operators and data sources: BfG, HLUG: Hessian Agency for the Environment and Geology, LUBW: Agency for the Environment, Measurements and Nature Conservation BadenWürttemberg, LUGW: State Office for the Environment, Water Management and Trade Supervision Rhineland-Palatinate, WSV).

\begin{tabular}{|c|c|c|c|c|}
\hline River & Name & River (km) & Interval & Operator \\
\hline Rhine & Karlsruhe temperature logger & 358.6 & $5 \mathrm{~min}$ & BfG/WSV \\
\hline Rhine & Karlsruhe station & 359.2 & Hourly & LUBW \\
\hline Rhine & Rheinhausen temperature logger & 392.5 & $5 \mathrm{~min}$ & BfG/WSV \\
\hline Rhine & Speyer temperature logger & 424.6 & $5 \min$ & BfG/WSV \\
\hline Neckar & Mannheim station & 2.95 & Hourly & LUBW \\
\hline Rhine & Worms temperature logger & 443 & $5 \mathrm{~min}$ & BfG/WSV \\
\hline Rhine & Worms station & 443.3 & Hourly & LUGW \\
\hline Rhine & Nierstein temperature logger & 481.7 & $5 \min$ & BfG/WSV \\
\hline Rhine & Mainz station & 498.5 & Hourly & LUGW \\
\hline Rhine & Mainz temperature loggers & 499 & $5 \mathrm{~min}$ & BfG/WSV \\
\hline Nahe & Dietersheim station & 3.54 & $10 \mathrm{~min}$ & LUWG \\
\hline Rhine & Kaub station & 546.2 & $15 \min$ & WSV \\
\hline Rhine & Kaub temperature logger & 546.2 & $5 \mathrm{~min}$ & BfG/WSV \\
\hline Rhine & Boppard temperature logger & 571.2 & $5 \mathrm{~min}$ & BfG/WSV \\
\hline
\end{tabular}

band model (see Sec. 4.2). Temperature, relative humidity and station pressure at weather stations in the research area were accessed from the German Meteorological Service (DWD) ${ }^{25}$ and linearly interpolated in space and time to obtain representative input parameters for each image that was corrected (see Ref. 26).

\section{Methods}

\subsection{Comparison with In Situ Measurements}

The ability to estimate bulk water temperatures with the remote sensing datasets was assessed by a comparison with in situ measurements at the acquisition time. The temperature is extracted from the remote sensing data at the location of the measurement station or its water outtake, respectively. For the characterization of the dataset, the mean and standard deviation of the temperature difference were calculated. Additionally, the RGBNIR classification was consulted to determine whether the remote sensing sensor actually acquired water temperature at that location.

\subsection{Calibration and Atmospheric Correction of the Aerial Survey}

When evaluating the local effect of the water temperature on the river ecosystem, it is necessary to obtain absolute bulk temperature values and their error estimates. The TIR camera sensor, however, acquires the brightness temperature of the observed surface $\left(T_{B}\right)$, including all radiances emitted into the line of sight of the camera. As water is a good, but not a perfect, absorber, it has an emissivity $(\varepsilon)$ between 0.96 and 0.99 in the 8 to $14 \mu \mathrm{m}$ region. ${ }^{27}$ Thus, a correction for the emissivity of the observed surface and the influence of the atmosphere is mandatory for calculation of kinetic surface temperatures $\left(T_{\text {surface }}\right)$. Based on the wavelength range of the 
TIR sensor, the low suspension load of the Rhine River, and only few waves with foam during the acquisition, an emissivity value of $\epsilon=0.99$ was chosen. After the correction for emissivity, two different approaches for correcting the datasets were tested with the aim of evaluating the efforts necessary for their calculation in relation to the quality of the results: As retrieval schemes for the river water temperature with regression between in situ and brightness temperatures was employed as well as straightforward atmospheric correction based on the physical parameters and modeling of the atmosphere.

When a sufficient number of in situ measurements is available for a dataset and the variability of the bias between remote sensing and in situ temperatures is low, a linear regression of the remotely sensed $T_{\text {surface }}$ based on in situ measurements is a possible option. This is a well-established method for the calibration of sea surface temperatures (SST) acquired by various satellite sensors. The SST or $T_{\text {surface }}$ is compared to in situ measurements ( $\left.T_{\text {insitu }}\right)$, the coefficients $\alpha_{0}$ and $\alpha_{1}$ for a linear relationship between $T_{\text {surface }}$ and $T_{\text {insitu }}$ are fitted using the least squares approach, and $T_{\text {surface }}$ is directly calibrated to the bulk temperature of the sea water.

$$
T_{\text {insitu }}=\alpha_{0}+\alpha_{1} T_{\text {surface }} \text {. }
$$

For the aerial survey, this was accomplished by randomly selecting half of the in situ measurements for calibration and calculating the coefficients for a linear regression between the aerial dataset and the in situ measurements. The surface temperatures from the aerial survey were then calibrated based on the discovered relationship and validated with the remaining in situ measurements. For SST products, using the linear relationship between $T_{\text {surface }}$ and bulk temperature is simple and effective, but it has been disputed and more advanced calibration algorithms have been developed. ${ }^{28-30}$ They take into account the water vapor content and vertical structure of the atmosphere or the state of the water surface and consider nonlinear errors due to the nonlinear relationships among brightness temperatures, water surface temperatures, and the state of the atmosphere. The nonlinear nature of these relationships, however, is more relevant on larger spatial scales ( $>5 \mathrm{deg}$ ) than the scale of the aerial survey, ${ }^{30}$ where a calibration based on linear regression seemed suitable.

An alternative to the calibration with in situ measurements is the correction for atmospheric influences during the acquisition. The surface temperature can be underestimated by up to 5 to $10^{\circ} \mathrm{C}$ if the influence of the atmosphere is not corrected. ${ }^{26}$ During the aerial survey, the difference was smaller, but could not be ignored (see Sec. 5.2). The temperature measured by the camera sensor is calibrated under laboratory conditions, but in reality, measured radiance and brightness temperature are affected by downwelling $L_{a}^{\text {down }}$ and upwelling $L_{a}^{\mathrm{up}}$ atmospheric radiances as well as the transmissivity $\tau$ of the atmosphere [Eq. (2)]. The temperature measured during the aerial survey has to be converted to radiance $L_{\text {meas }}$ with Planck's radiation law and corrected for the emissivity $(\epsilon)$ of the surface and the atmosphere between surface and sensor altitude $\left(L_{a}^{\mathrm{up}}, L_{a}^{\mathrm{down}}\right.$, $\tau$ ) (Refs. 31 and 32, references to the wavelength are omitted).

$$
L_{\text {meas }}=\left(\varepsilon L_{\text {surface }}+(1-\varepsilon) L_{a}^{\text {down }}\right) \tau+L_{a}^{\text {up }} .
$$

The atmospheric parameters in Eq. (2) were modeled based on radiative transfer equations by the software MODTRAN ${ }^{\circledR}$ 5.3.2. It is widely used to correct single-band thermal data acquired by satellite and airplane; for some datasets, predefined input parameters and weather data are available (e.g., in the AtmCorr Calculator, ${ }^{32}$ ATCOR).

Individual atmospheric parameters were calculated for each image of the aerial survey; weather data (air temperature, station pressure, and relative humidity) from a DWD meteorological station was linearly interpolated for the acquisition time and center point of each temperature raster and combined with a standard atmospheric profile (U.S. Standard) as input for MODTRAN ${ }^{\circledR}$ 5.3.2. When computing $L_{a}^{\text {down }}$ and $L_{a}^{\text {up }}$, the radiances were integrated over the wavelength and the response function of the sensor as suggested by McCarville et al. ${ }^{33}$ The temperature raster was then corrected based on Eq. (2) and compared to in situ measurements where available.

The atmospheric correction does not take into account other processes at the water surface that can influence the acquired brightness temperatures. These are the difference between the skin temperature at the water surface measured by the TIR sensor and the subsurface bulk water 
temperature represented by the in situ measurements, the possible stratification of the water, or the effects of viewing angle, wind, waves, and foam on the emissivity.

\subsection{Artificial Satellite Datasets}

One aim of this study was to test the methods for the detection of inflows for datasets with different resolutions and noise levels, but thermal images from satellites were not available at the same point of time as the aerial survey. Hence, several artificial datasets that resemble actual datasets provided by the Landsat missions were created by degrading or upscaling ${ }^{34}$ the TIR and RGBNIR raster data of the aerial survey. For the upscaling of thermal raster data, a spatial filter designed to simulate the sensor response should be applied, ${ }^{35,36}$ but block averaging is commonly used and gives satisfactory results. ${ }^{36-38}$ The brightness temperatures acquired by the aerial survey were used as input, as the effect of the exponential term in the Planck's radiation law to convert between radiance and temperature should be small and there is no obvious difference between the scaling of temperature and radiance. ${ }^{38}$ It was implemented by using the functions measure.block_reduce from the skimage package ${ }^{39}$ and the module gdal from the osgeo package ${ }^{40}$ in python. ${ }^{41}$ Subsequently, a random noise mask with a normal distribution, with zero as mean value and a standard deviation equal to the desired noise equivalent differential temperature $(\mathrm{NE} \Delta T)$ was created and added to the degraded raster data with the new, lower resolution. Of the final datasets, one dataset was created with the NE $\Delta T$ and acquired resolution of Landsat ETM+ thermal data. ${ }^{42,43}$ The other two datasets received the spatial resolution of the new Landsat TIRS sensor $(100 \mathrm{~m})$, with two different $\mathrm{NE} \Delta T: 0.4^{\circ} \mathrm{C}$, required during the planning phase of the satellite mission, ${ }^{44}$ and the actually evaluated $0.1^{\circ} \mathrm{C} .{ }^{45}$ Table 2 assembles the characteristics of the original survey data and the three artificial satellite datasets. While the mean temperature remained almost the same, the block averaging reduced the temperature range of the dataset and the standard deviation decreased with increasing pixel size rather than with increasing $\mathrm{NE} \Delta T$ (see Ref. 38).

\subsection{Inflow Detection}

For the detection of inflows along the Rhine River, the mean and the standard deviation of the water temperature for every $100 \mathrm{~m}$ were calculated from the distributed longitudinal profile (see Fig. 3). For every $100 \mathrm{~m}$ of the longitudinal profile, the temperature from evenly spaced points across the whole river was collected and summary statistics (mean $\mu_{100 \mathrm{~m}}$ and standard deviation $\left.\sigma_{100 \mathrm{~m}}\right)$ were calculated to represent the characteristics of the river temperature and further analyzed.

The change point analysis is a suitable method to identify the points where the statistical properties within the dataset change. ${ }^{46}$ The applied pruned exact linear time method offers exact segmentation of datasets to identify several change points with computational costs linear to the number of data points. ${ }^{46}$ The change point package ${ }^{47}$ of the statistical program $\mathrm{R}$ (Ref. 48) was then used to apply the change point analysis of the mean river temperature and to test whether this method could identify inflows even without prior knowledge of them. A standardized method was implemented to set the threshold for the change detection so that the change

Table 2 Overview of the evaluated remote sensing datasets with their spatial resolution and sensor noise.

\begin{tabular}{lcc}
\hline \hline Dataset & Spatial resolution $(\mathrm{m})$ & $\mathrm{NE} \Delta T\left({ }^{\circ} \mathrm{C}\right)$ \\
\hline Aerial survey & 5 & 0.025 \\
Landsat ETM+ (evaluated NE $\Delta T)$ & 60 & 0.22 \\
Landsat TIRS (evaluated NE $\Delta T)$ & 100 & 0.1 \\
Landsat TIRS (required NE $\Delta T$ ) & 100 & 0.4 \\
\hline \hline
\end{tabular}

$\mathrm{NE} \Delta T$, noise equivalent differential temperature. 


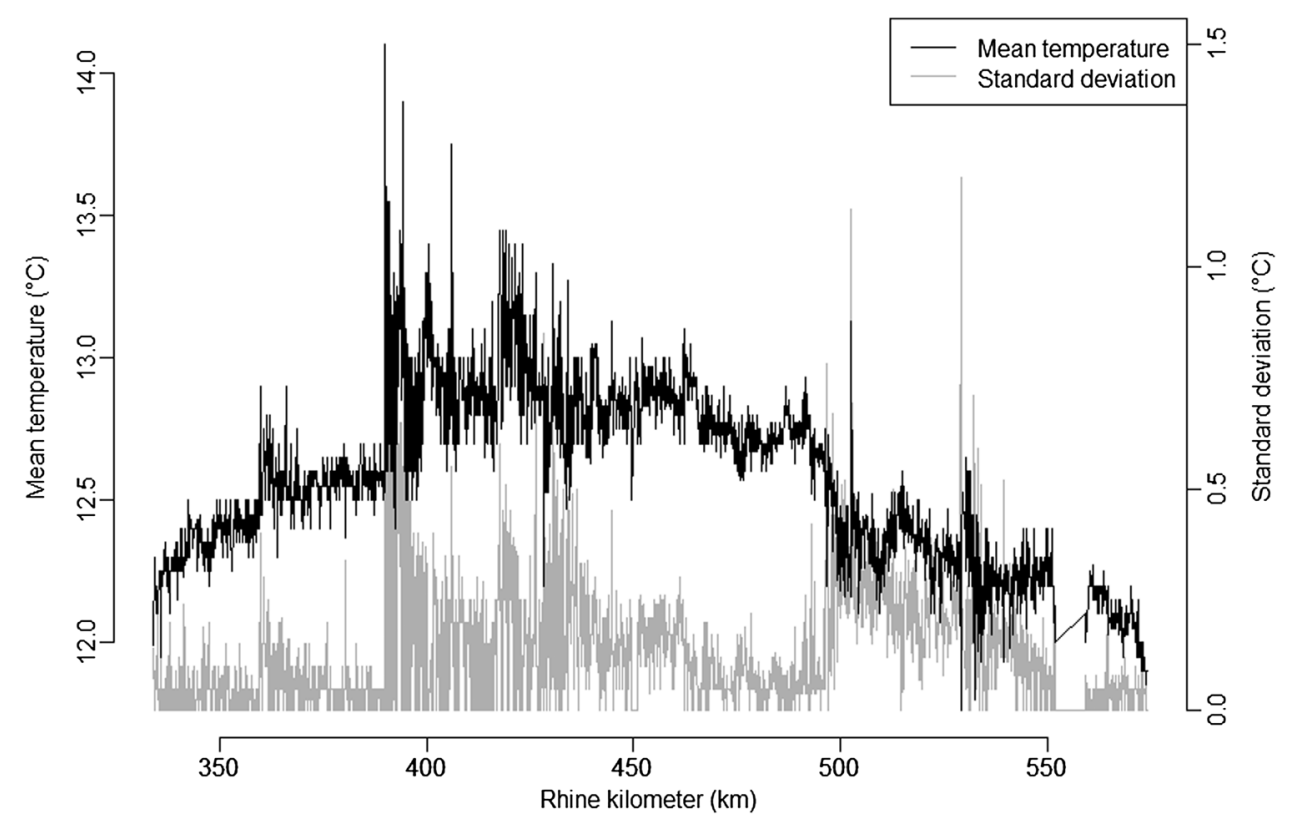

Fig. 3 The mean temperature and standard deviation of the temperature along the distributed longitudinal profile of the Rhine River, extracted from the original aerial survey acquired on October 31, 2013 (data source: BfG). The changes of mean temperature and standard deviation show the effect of inflows with differing water temperatures on the river temperature.

detection of different datasets could be compared: different threshold values were tested and the threshold was reached when the number of change points converges asymptotically to a stable value. Compared to other methods to define the penalty value, this approach proved to detect the position of the known inflows the best and was the least affected by the variance of the dataset. The change point analysis of the mean was conducted for the $\mu_{100 \mathrm{~m}}$ of all original and artificial datasets (see Sec. 4.3). The locations of known potential inflows ${ }^{21}$ served as validation data and counted as detected if a change point was found within $5 \mathrm{~km}$ of a known potential inflow. The change point analysis of the mean and variance proved to result in too many change points as the variance could also change long after the inflow based on the distribution of the water plume.

Additionally, the simple standard deviation of the water temperature for each $100 \mathrm{~m}$ section $\left(\sigma_{100 \mathrm{~m}}\right)$ could be used to evaluate the mixing processes of water bodies. After an inflow, the lateral flow of the main stream and the plume of the inflow are indicated by the increasing variability of the water temperatures. Ideally, a certain distance after the outlet, the water bodies have mixed and the stream exhibits a nearly uniform temperature with a low standard deviation in the distributed longitudinal profile (see also Fig. 3). Thus, the standard deviation of the water temperature across the river can serve as an indicator for the existence of plumes or uniform streams. As a threshold for uniform river sections, the mean plus the standard deviation of all $\sigma_{100 \mathrm{~m}}$ of the longitudinal profile was chosen.

\section{Results and Discussion}

\subsection{Characteristics of the Dataset}

Throughout the original aerial survey, a systematical error in the form of a temperature decrease could be observed toward the border area of the single scenes. The range was -0.1 to $-0.2^{\circ} \mathrm{C}$ compared to the temperature in the center area of the overlapping neighboring scene. This phenomenon could be observed due to the constant emissivity and only slowly changing temperature of the river water in contrast to the changing emissivities and $T_{B}$ of the varying land surfaces. The spatial allocation of the pixels was not necessarily accurate as the spatial accuracy was only $\sim 15 \mathrm{~m}$, but even after applying a 3 pixel $\times 3$ pixel averaging filter, the systematical error was visible. Possible causes for this error include the influence of varying observation 
angles on the atmospheric parameters (up- and downwelling atmospheric radiances and transmissivity) and emissivity or sensor degradation toward the border areas. The correction of one test scene with MODTRAN ${ }^{\circledR} 5.3 .2$ and different observation angles showed that the look angle off-nadir at the border of the scene ( $20 \mathrm{deg}$ ) caused no changes in transmissivity, but a slightly higher upwelling radiance. This should actually cause higher brightness temperature at the bor$\operatorname{der}\left(+0.4^{\circ} \mathrm{C}\right)$. On the other hand, water shows a decrease of emissivity with increasing viewing angle ${ }^{49}$ which could cause decreasing brightness temperatures. This effect has been calculated to be only around -0.1 to $-0.2^{\circ} \mathrm{C}$. The observation could also be caused by natural vignetting that is more prominent for short focal lengths and wide angle lens as used for the acquisition of the TIR images. Based on these estimations that have an equally large uncertainty, the observed systematic error remains partly unexplained and a sensor error cannot be eliminated.

\subsection{Evaluation of Original, Calibrated, and Corrected Aerial Survey Data}

For the evaluation of the usefulness of the remote sensing temperatures and the correction methods, $T_{B}$ acquired by the aerial survey and corrected $T_{\text {surface }}$ were compared to the water temperatures measured in situ. $T_{B}$ and $T_{\text {surface }}$ actually represent the skin temperature of the water surface, while the in situ stations and temperature loggers measure the subsurface (bulk) water temperature at 1 to $2 \mathrm{~m}$ depths. All datasets were preprocessed as described in Sec. 4.2, and the difference between the temperatures acquired by the aerial survey, $T_{\text {aerial }}$, and the in situ measurements from 19 stations at the time of acquisition was calculated $(\Delta T)$. The mean difference $(\mu)$ between the uncorrected original dataset from the aerial survey and the in situ temperature measurements was $-1.23^{\circ} \mathrm{C}$ with a standard deviation $(\sigma)$ of $0.54^{\circ} \mathrm{C}$. The aerial data underestimated the real water temperature quite uniformly over the survey area. The in situ measurement stations where $\Delta T$ was outside $\mu \pm \sigma$ were investigated more closely. Of these stations, two temperature measurement stations located at Rheinhausen and Worms had to be omitted as it is unclear which water body they represent. Both river sections are characterized by a parallel flow of inflow plumes and river water, and the in situ measurements are situated at the boundary layer between the two water bodies. The authors believe that the underwater measurements at the two locations do not represent the surface water temperature as the vertical mixing of the water layers at this location is incomplete. Without the measurements in question, the variance of $\Delta T$ was reduced (see Fig. 4) and they were omitted for the remaining evaluation of the aerial dataset. A correction for the emissivity improved the mean $\Delta T$ to $-0.85^{\circ} \mathrm{C}$, while the standard deviation, as expected, remained almost the same at $0.15^{\circ} \mathrm{C}$.

The remaining $\Delta T$ could be due to the atmospheric influence and a difference between surface and bulk temperature. At mean runoff, vertical mixing takes place in the Rhine River and prevents a stratification of water bodies: even when low sun angles occurred and hard shadows

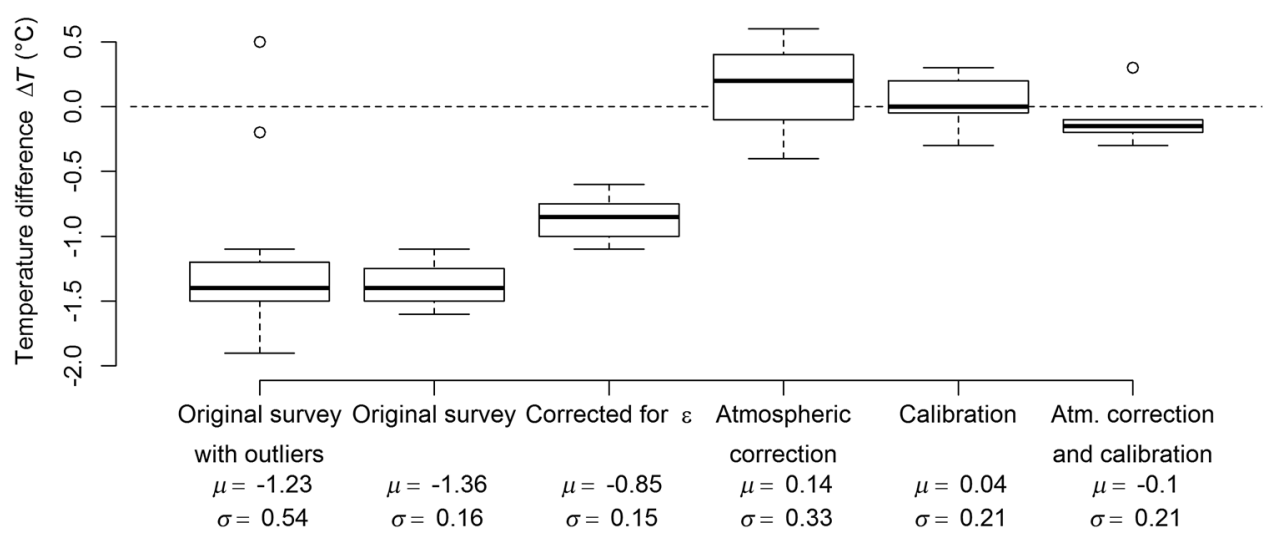

Fig. 4 Boxplot of the temperature differences between aerial survey and in situ measurements $\left(\Delta T=T_{\text {aerial }}-T_{\text {insitu }}\right)$, showing the effects of the correction steps on $\Delta T$ (black line: median, bottom and top of the box: first and third quartiles, whiskers: \pm 1.58 interquartile range, roughly a $95 \%$ confidence interval). 
were visible in the RGBNIR data on the water surface, no temperature differences were detectable in the TIR data at the shadow border. Based on this assumption of vertical mixing, differences between subsurface and bulk water temperature were neglected. However, differences between the subsurface and the cooler skin temperature (skin effect) can occur in the dimension of $0.1^{\circ} \mathrm{C}$ (daytime) to $0.5^{\circ} \mathrm{C}$ (nighttime), ${ }^{50}$ but could not be investigated in the absence of additional in situ measurements of the skin temperature.

The correction of the aerial survey based on a linear regression between half of the in situ measurements and the corresponding TIR temperatures should also correct for the skin effect and was quite successful: After the correction for emissivity and the calibration with $\alpha_{0}=1.81$ and $\alpha_{1}=0.93$, the mean $\Delta T$ between the aerial survey and the second half of the in situ temperatures selected for the validation was $0.04 \pm 0.21^{\circ} \mathrm{C}$ (see also Fig. 5). On the other hand, the atmospheric correction slightly overestimates the atmospheric influence $\left(\Delta T=0.14 \pm 0.33^{\circ} \mathrm{C}\right)$. With a subsequent calibration based on linear regression between the temperatures corrected for the atmosphere and in situ measurements $\left(\alpha_{0}=4.81, \alpha_{1}=0.64\right)$, mean $\Delta T$ was reduced to $-0.10 \pm$ $0.21^{\circ} \mathrm{C}$ when comparing the corrected and calibrated temperatures to the validation in situ data. As the atmospheric correction of the raster temperature images was calculated individually, the values of $\Delta T$ did not change uniformly (see also the increased standard deviation of $\Delta T$ for the atmospheric correction in Fig. 4). Hence, mean $\Delta T$ is not the same as for the calibration only. The resulting mean differences were similar to other studies, ${ }^{12,13}$ but with a lower variance of the differences. The authors conclude that the relationship between remote sensing and in situ temperatures is similar for all measurement stations and temperature loggers in this analysis, except the stations excluded before (see beginning of Sec. 5.2).

The artificial degraded datasets corrected for emissivity were also compared to in situ measurements (see Fig. 6). The degrading of both the spatial resolution and the sensor noise lead to a decreasing remote sensing temperature that underestimates the actual water temperature at the in situ measurement stations. This may be due to mixed pixels of water and land surface at the river shore, which had a lower $T_{B}$ at acquisition time, and the measurement stations that were mostly located close to the river shore. The standard deviation of the difference between remote sensing temperatures and in situ measurement increased with the pixel size in this comparison (see Fig. 6), but it is still lower than the standard deviation of the original Landsat ETM+ scenes for the Rhine River $\left(\sigma=1.3^{\circ} \mathrm{C}\right)$ from a previous study, ${ }^{6}$ which are additionally affected by the atmosphere and sensor characteristics.

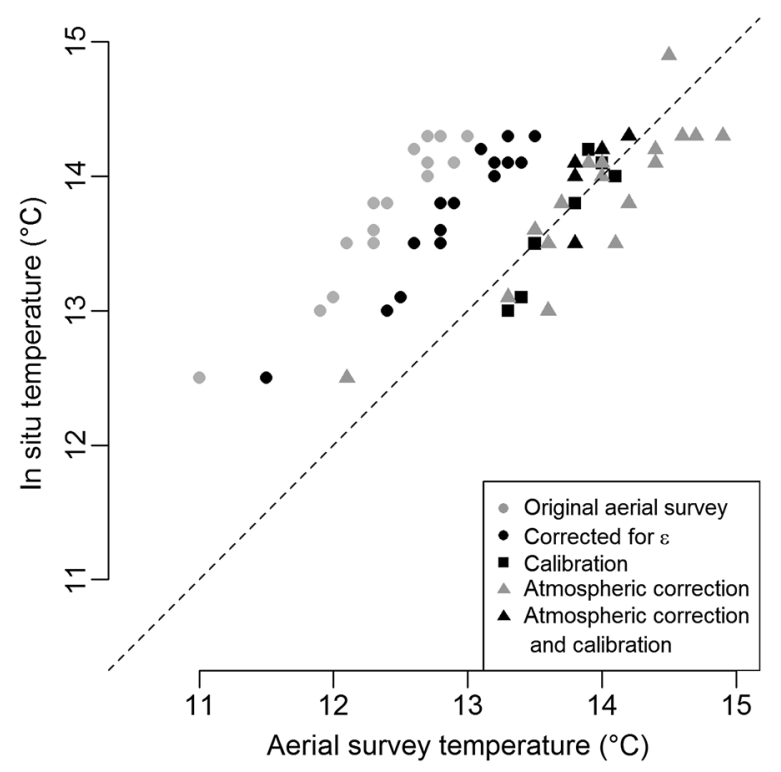

Fig. 5 Uncorrected and corrected temperatures from the aerial survey versus in situ measurements. The data points of the original survey show that a correction is necessary, but the bias is fairly uniform and the results of calibration and atmospheric correction lie very close to the line through the origin. 
Fricke and Baschek: Temperature monitoring along the Rhine River based on airborne thermal...

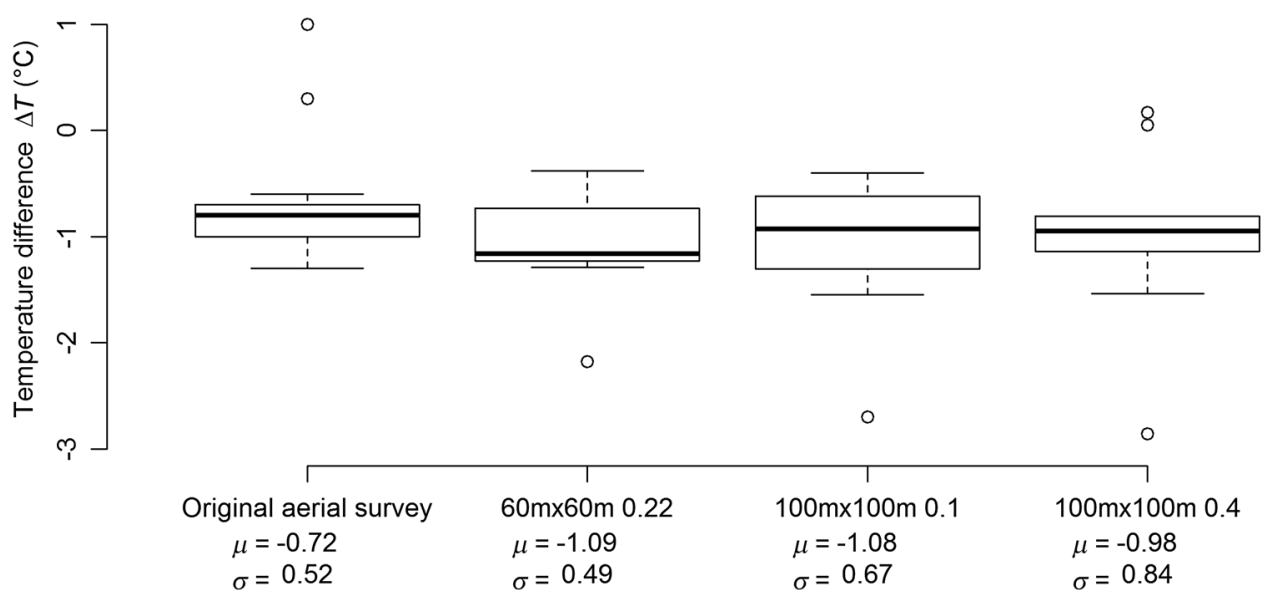

Fig. 6 Boxplot of the temperature differences between the in situ measurements and the four different remote sensing dataset corrected for emissivity $\left(\Delta T=T_{\text {dataset }}-T_{\text {insitu }}\right.$ ) (black line: median, bottom and top of the box: first and third quartiles, whiskers: \pm 1.58 interquartile range, roughly a $95 \%$ confidence interval).

\subsection{Inflow Detection}

The majority of the 20 known inflows could be detected by the change point analysis of the mean: the sensitivity of the change point analysis to the changes of the mean temperature from the distributed longitudinal profile seems to be sufficient as the mean includes any temperature changes across the river caused by inflows and dischargers (e.g., Fig. 7 and Table 3). The change point analysis also detects false positive change points. If one inflow does not mix well with the main river stream and causes several $T_{\text {mean }}$ changes depending on the distribution of the plume of the inflow, several change points are detected by this method (for example, downstream of the power plant in Philippsburg in Fig. 7). This also shows that an inflow plume can change its apparent size and persist over a long distance after the inflow source. On the other hand, when several inflows with a similar effect on the river water temperature are located close to each other,

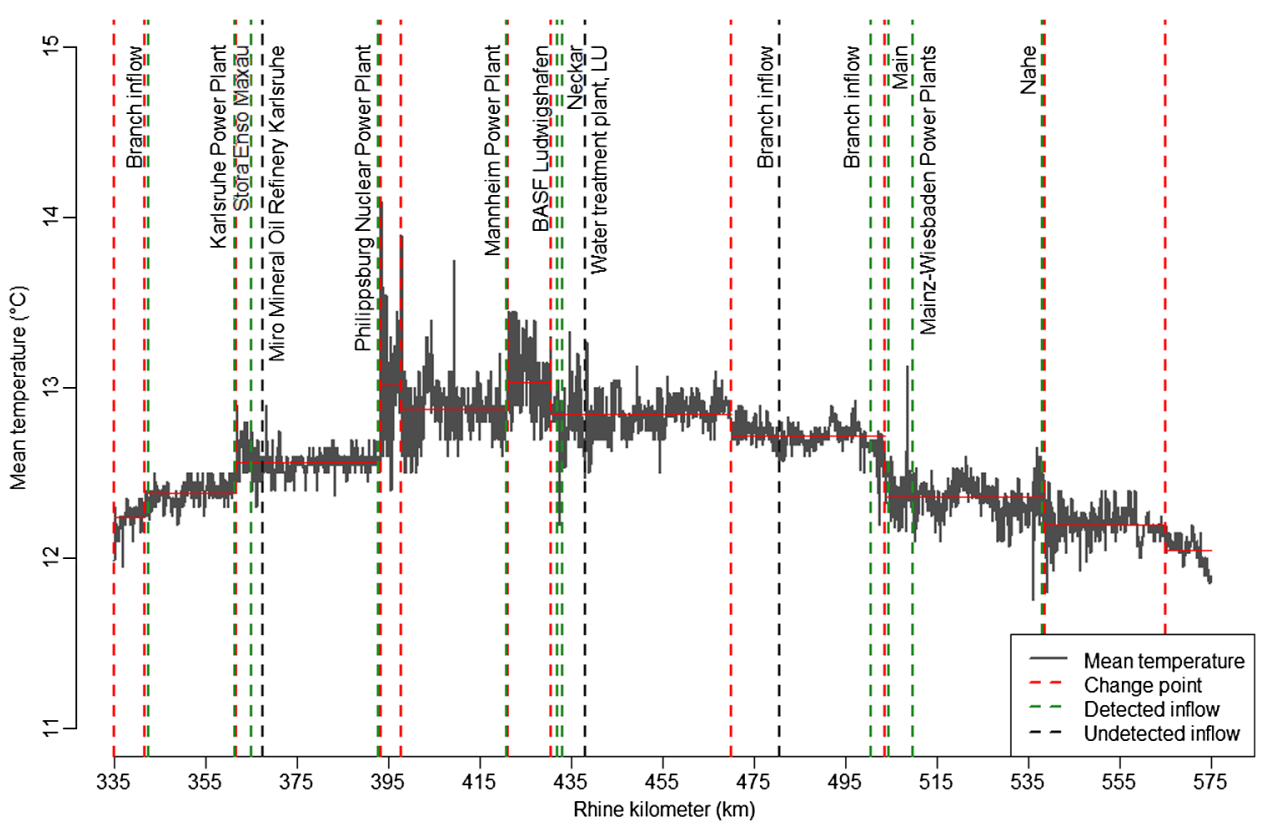

Fig. 7 Change point analysis of the mean water temperature from the original aerial survey. $80 \%$ of the inflows were successfully detected (marked by green dashed lines) by change points (red dashed lines). 
Table 3 Results of the change point analysis of the mean river temperature from the different remote sensing datasets: mainly the increasing noise level of the datasets caused an increasing number of missed inflows and false positive change points.

\begin{tabular}{lcccccc}
\hline \hline & \multicolumn{2}{c}{ Inflows } & & \multicolumn{3}{c}{ Change points } \\
\cline { 2 - 3 } \cline { 5 - 7 } Dataset (resolution and NE $\Delta T$ ) & Detected (\%) & Undetected (\%) & Number & Correct (\%) & Incorrect (\%) \\
\hline $5 \mathrm{~m} \times 5 \mathrm{~m}, 0.025$ & 80 & 20 & & 14 & 83.3 & 16.7 \\
$60 \mathrm{~m} \times 60 \mathrm{~m}, 0.22$ & 45 & 55 & & 16 & 62.5 & 37.5 \\
$100 \mathrm{~m} \times 100 \mathrm{~m}, 0.1$ & 80 & 20 & & 18 & 77.8 & 22.2 \\
$100 \mathrm{~m} \times 100 \mathrm{~m}, 0.4$ & 45 & 55 & & 12 & 66.7 & 33.3 \\
\hline \hline
\end{tabular}

only one change point is detected and the inflows cannot be identified separately (for example, in Karlsruhe and Mannheim/Ludwigshafen).

The degrading of the raster datasets (sensor noise and spatial resolution) seemed to have different effects on the ability to detect inflows (see Table 3). With the chosen threshold method, a higher NE $\Delta T$ leads to a larger number of false positive change points, when nonexistent inflows are instead caused by sensor noise and mixed pixels. Their influence seems to override the effect of the spatial resolution that should reduce the variance by averaging the temperature values.

In the dataset with the higher resolution, i.e., the original aerial dataset, the effects of the inflows could be detected in the standard deviation of every $100 \mathrm{~m}$ part (see power plant Philippsburg, Neckar River at Mannheim, Main River, in Fig. 8): only after a certain distance, the mixing of the main stream and the inflow is completed and the standard deviation of the distributed longitudinal profile falls below the threshold (defined in Sec. 4.4). Especially, the river part $70 \mathrm{~km}$ downstream of the power plant in Phillipsburg and the river part from

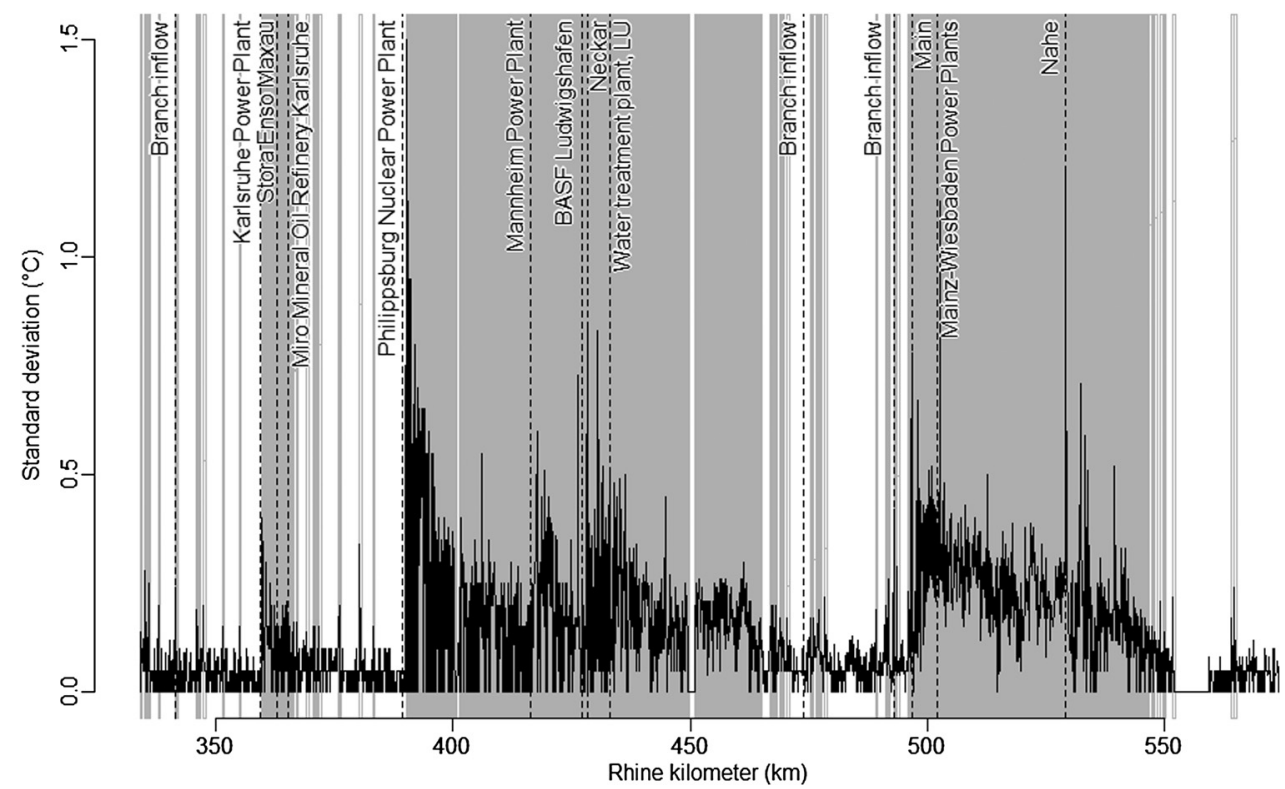

Fig. 8 The standard deviation of the temperature along the distributed longitudinal profile of the Rhine River and the identified inflow plumes for the dataset with a spatial resolution of $5 \mathrm{~m} \times 5 \mathrm{~m}$ (data source: $\mathrm{BfG}$ ). In the first river section, $\sigma$ is relatively low and the temperature distribution across the river uniform except shortly after the inflows in Karlsruhe. However, from Philippsburg on, temperature differences across the river are prevalent and until $20 \mathrm{~km}$ after the Nahe inflow, the river is thoroughly mixed only for short passages. 
Mainz and the Main River inflow until the Middle Rhine Valley around Rh-km 550 are characterized by inflows with persistent plumes and with a large impact on the variance of the river temperature. The temperature plumes of the inflows prevail until the next inflow and overlay each other. With a lower spatial resolution and more sensor noise, the ability to detect plumes abated as they could not be differentiated from the variance inherent to the dataset.

\section{Conclusion}

When evaluating the ability of the water temperatures acquired by aerial survey of the Rhine River to estimate bulk water temperatures and comparing the remote sensing surface temperatures with in situ measurements, it becomes apparent due to the temperature difference $\left(-1.23 \pm 0.54^{\circ} \mathrm{C}\right)$ that correction for the emissivity of the water surface, the atmosphere, and other effects (skin effect, lens error) is necessary. The mean bias after correction for emissivity $\left(-0.85 \pm 0.15^{\circ} \mathrm{C}\right)$ is similar to that of Landsat ETM+ data of the research area, ${ }^{6}$ but the original satellite dataset from several acquisition dates has a much higher variance compared to the aerial data.

The results of the calibration and correction of the aerial temperature dataset were comparable or better than that for other studies. ${ }^{12,13}$ The calibration based on linear regression between in situ measurements and surface temperatures provided the best results and achieved a bias of $0.04 \pm 0.21^{\circ} \mathrm{C}$ in the validation, with a maximum range of $\pm 0.3^{\circ} \mathrm{C}$. The automatization of calibration based on in situ measurements, for example, for larger datasets or frequent data service, would be possible for limited areas with a fairly homogeneous atmosphere when a sufficient amount of in situ measurements, distributed over the investigated area, is available. In this study, additional measurements were provided by temporary data loggers, but they may not be available for other remote sensing datasets.

Atmospheric correction proved to be inferior to the calibration but still gave satisfying results. It reduced the mean temperature difference between the corrected aerial survey and in situ measurements to $0.14 \pm 0.33^{\circ} \mathrm{C}$, similar to the correction of satellite data for the same area. ${ }^{6}$ While the expenditures for in situ measurements are lower for this method, it requires information about the atmospheric situation and more effort for the correction. Also, in this case, it overestimated the in situ bulk temperatures and did not take other influences than the atmosphere into account.

The evaluation of the observed outliers demonstrated how important the careful selection of a representative pixel of nearby water is for the comparison with in situ measurements. The effect of the omitted stations on the mean temperature difference and standard deviation was similar to the effect of the different correction methods. In areas with a heterogeneous temperature distribution, either a high resolution of the remote sensing data or a careful selection of measurement stations is required.

With regard to the upscaling of the remote sensing datasets, the degradation of spatial resolution and increasing sensor noise caused slightly lower temperatures due to the colder surroundings of the water bodies and higher variance. Areas with uniform water temperature also seemed well represented by datasets with lower resolution. When comparing the artificial datasets and in situ measurements, the mean differences were in the same dimension as for the data sets with a higher resolution, but with a higher variance.

The detection of change points with the change point analysis proved to find most of the known inflows used for validation in the aerial survey (80\%). In the artificial satellite datasets, temperature signals from the inflows are evened out by upscaling through the block averaging or disappear due to the increasing sensor noise (especially for the datasets $60 \mathrm{~m} \times 60 \mathrm{~m}, 0.22$ and $100 \mathrm{~m} \times 100 \mathrm{~m}, 0.4$ ), which seems to have a larger effect on the number of detected inflows than the spatial resolution. The number of false positives also increases more strongly with sensor noise than with increasing pixel size from $<20 \%$ to almost $40 \%$ false positive detections. Additionally, the atmospheric influence on the satellite datasets that were not modeled here could hinder the change point detection. The longitudinal profiles from datasets with lower spatial resolution and higher sensor noise would require smoothing to avoid the false positive detections, which, in turn, would reduce the sensitivity of actual inflow detection. Further steps to be undertaken will depend on the dataset and the desired result. 
The investigation of mixing processes based on the standard deviation of the water temperature across the river was successful for the original data from the aerial survey. As soon as the mean standard deviation is higher than the temperature difference or signal to be observed, the increased variance of the degraded dataset prevents the identification of plumes with small temperature differences. Thus, using the standard deviation of distributed longitudinal profiles for the detection of plumes and mixing processes is only feasible for datasets with a sufficient spatial resolution and low sensor noise such as the original aerial survey dataset.

\section{Acknowledgments}

This study was carried out for the research project "Remote sensing of water surface temperature" of the Federal Institute of Hydrology (BfG), Germany. The authors would like to thank all involved departments of BfG, the Federal Waterways and Shipping Administration (WSV), and the German Meteorological Service (DWD) for the allocation of in situ measurement and weather data.

\section{References}

1. B. W. Webb et al., "Recent advances in stream and river temperature research," Hydrol. Processes 22(7), 902-918 (2008).

2. IKSR, "Aktueller Kenntnisstand über mögliche Auswirkungen von Änderungen des Abflussgeschehens und der Wassertemperatur auf das Ökosystem Rhein und mögliche Handlungsperspektiven," IKSR-Report 204, International Commission for the Protection of the Rhine against Pollution, Coblenz (2013).

3. C. Merchant, "Thermal remote sensing of sea surface temperature," Chapter 15 in Thermal Infrared Remote Sensing-Sensors, Methods, Applications, C. Künzer and S. Dech, Eds., pp. 287-313, Springer, Dordrecht Heidelberg (2013).

4. W. J. Emery et al., "Estimating sea surface temperature from infrared satellite and in situ temperature data," Bull. Am. Meteorol. Soc. 82(12), 2773-2785 (2001).

5. R. Díaz-Delgado et al., "Long time series of Landsat images to reconstruct river surface temperature and turbidity regimes of Guadalquivir Estuary," in IEEE Int. Geoscience and Remote Sensing Symp., pp. 233-236 (2010).

6. K. Fricke and B. Baschek, "Water surface temperature profiles for the Rhine River derived from Landsat ETM+ data," Proc. SPIE 8887, 88870E (2013).

7. V. Wawrzyniak, H. Piegay, and A. Poirel, "Longitudinal and temporal thermal patterns of the French Rhone River using Landsat ETM+ thermal infrared images," Aquat. Sci. 74(3), 405-414 (2012).

8. F. Despini and S. Teggi, "Analysis of temperature maps of waterbodies obtained from ASTER TIR images," Int. J. Remote Sens. 34(9-10), 3636-3653 (2013).

9. N. D. Walker et al., "Effects of river discharge, wind stress, and slope eddies on circulation and the satellite-observed structure of the Mississippi river plume," J. Coastal Res. 21(6), 1228-1244 (2005).

10. A. Reinart and M. Reinhold, "Mapping surface temperature in large lakes with MODIS data," Remote Sens. Environ. 112(2), 603-611 (2008).

11. U. Mallast et al., "How to identify groundwater-caused thermal anomalies in lakes based on multi-temporal satellite data in semi-arid regions," Hydrol. Earth Syst. Sci. Discuss. 10(4), 4901-4949 (2013).

12. V. Wawrzyniak et al., "Prediction of water temperature heterogeneity of braided rivers using very high resolution thermal infrared (TIR) images," Int. J. Remote Sens. 34(13), 48124831 (2013).

13. C. E. Torgersen et al., "Airborne thermal remote sensing for water temperature assessment in rivers and streams," Remote Sens. Environ. 76(3), 386-398 (2001).

14. S. P. Loheide and S. M. Gorelick, "Quantifying stream-aquifer interactions through the analysis of remotely sensed thermographic profiles and in situ temperature histories," Environ. Sci. Technol. 40(10), 3336-3341 (2006). 
Fricke and Baschek: Temperature monitoring along the Rhine River based on airborne thermal...

15. J. Tan and K. A. Cherkauer, "Assessing stream temperature variation in the Pacific Northwest using airborne thermal infrared remote sensing," J. Environ. Manage. 115, 206-216 (2013).

16. D. Tonolla et al., "Thermal heterogeneity in river floodplains," Ecosystems 13(5), 727-740 (2010).

17. D. Tonolla et al., "Linking fish assemblages and spatiotemporal thermal heterogeneity in a river-floodplain landscape using high-resolution airborne thermal infrared remote sensing and in-situ measurements," Remote Sens. Environ. 125, 134-146 (2012).

18. K. A. Cherkauer et al., "Assessing satellite-based and aircraft-based thermal infrared remote sensing for monitoring Pacific Northwest river temperature," J. Am. Water Resour. Assoc. 41(5), 1149-1159 (2005).

19. J. E. Kay et al., "Accuracy of lake and stream temperatures estimated from thermal infrared images," J. Am. Water Resour. Assoc. 41(5), 1161-1175 (2005).

20. R. N. Handcock et al., "Accuracy and uncertainty of thermal-infrared remote sensing of stream temperatures at multiple spatial scales," Remote Sens. Environ. 100(4), 427-440 (2006).

21. BUND, "Studie_Wärmelast Rhein,” 2009, http://www.bund-rlp.de/uploads/media/bund_ waerme_lang_bild.pdf (19 August 2013).

22. IKSR, "Vergleich der Wärmeeinleitungen 1989 und 2004 entlang des Rheins," IKSRReport 151d, International Commission for the Protection of the Rhine against Pollution, Coblenz (2006).

23. P. Hardenbicker et al., "Modellierung von Wassertemperatur und Planktondynamik im Rhein," in KLIWAS-Auswirkungen des Klimawandels auf Wasserstraßen und Schiffahrt in Deutschland, BMVBS, Ed., pp. 87-92, Bonn, Germany, http://www.kliwas.de/KLIWAS/ DE/Service/Downloads/Publikationen/tagungsband_oktober_2011_berlin.pdf?_blob= publicationFile (19 August 2013).

24. IKSR, "Darstellung der Entwicklung der Rheinwassertemperaturen auf der Basis validierter Temperaturmessungen von 1978 bis 2011," IKSR-Report 209, International Commission for the Protection of the Rhine against Pollution, Coblenz (2013).

25. German Meteorological Service (DWD), Climate data-online-free, 2014, http://www .dwd.de (7 October 2014).

26. J. A. Barsi, J. L. Barker, and J. R. Schott, "An atmospheric correction parameter calculator for a single thermal band earth-sensing instrument," in IEEE Int. Geoscience and Remote Sensing Symp., pp. 3014-3016 (2003).

27. J. W. Salisbury and D. M. D'Aria, "Emissivity of terrestrial materials in the $8-14 \mu \mathrm{m}$ atmospheric window," Remote Sens. Environ. 42, 83-106 (1992).

28. C. J. Donlon et al., "Toward improved validation of satellite sea surface skin temperature measurements for climate research," J. Clim. 15(4), 353-369 (2002).

29. C. Merchant and P. Le Borgne, "Retrieval of sea surface temperature from space, based on modelling of infrared radiative transfer: capabilities and limitations," J. Atmos. Oceanic Technol. 21, 1734-1746 (2004).

30. C. Merchant et al., "Retrievals of sea surface temperature from infrared imagery: origin and form of systematic errors," Q. J. R. Meteorolog. Soc. 132, 1205-1223 (2006).

31. J. C. Jiménez-Muñoz and J. A. Sobrino, "A generalized single-channel method for retrieving land surface temperature from remote sensing data," J. Geophys. Res. Atmos. 108(D22), 4688 (2003).

32. J. A. Barsi et al., "Validation of a web-based atmospheric correction tool for single thermal band instruments," Proc. SPIE 5882, 58820E (2005).

33. D. C. McCarville et al., "Atmospheric correction of Landsat thermal infrared data: a calculator based on North American Regional Reanalysis (NARR) data," in Proc. of the American Society for Photogrammetry and Remote Sensing Conf., p. 12 (2011).

34. M. D. Nelson et al., "Effects of satellite image spatial aggregation and resolution on estimates of forest land area," Int. J. Remote Sens. 30(8), 1913-1940 (2009).

35. C. O. Justice et al., "Spatial degradation of satellite data," Int. J. Remote Sens. 10(9), 15391561 (1989). 
36. W. F. Zhan et al., "Disaggregation of remotely sensed land surface temperature: literature survey, taxonomy, issues, and caveats," Remote Sens. Environ. 131, 119-139 (2013).

37. S. Teggi, "A technique for spatial sharpening of thermal imagery of coastal waters and of watercourses," Int. J. Remote Sens. 33(10), 3063-3089 (2012).

38. Y. Liu, T. Hiyama, and Y. Yamaguchi, "Scaling of land surface temperature using satellite data: a case examination on ASTER and MODIS products over a heterogeneous terrain area," Remote Sens. Environ. 105(2), 115-128 (2006).

39. S. van der Walt et al., "scikit-image: image processing in Python," PeerJ 2, e453 (2014).

40. H. Butler, "GDAL, version 1.9.2," 2012, http://www.gdal.org (8 May 2015).

41. Python Software Foundation, "Python, version 2.7.3," 2010, http://www.python.org (8 May 2015)

42. J. A. Barsi et al., "Landsat TM and ETM+ thermal band calibration," Can. J. Remote Sens. 29(2), 141-153 (2003).

43. U. S. Geological Survey, "Frequently asked questions about the Landsat missions: what are the band designations for the Landsat satellites?," U.S. Geological Survey, 2014, http:// landsat.usgs.gov/band_designations_landsat_satellites.php (13 January 2015)

44. J. R. Irons, J. L. Dwyer, and J. A. Barsi, "The next Landsat satellite: the Landsat Data Continuity Mission," Remote Sens. Environ. 122, 11-21 (2012).

45. J. R. Irons, "Landsat 8: promise and performance," in 2013 Fall Meeting, AGU, Abstract B53G-02 (2013).

46. R. Killick, P. Fearnhead, and I. A. Eckley, "Optimal detection of changepoints with a linear computational cost," J. Am. Stat. Assoc. 107(500), 1590-1598 (2012).

47. R. Killick and I. Eckley, "changepoint: an R package for changepoint analysis," J. Stat. Softw. 58(3), 1-19 (2014).

48. R Development Core Team, "R: a language and environment for statistical computing," R Foundation for Statistical Computing, Vienna, Austria, 2008, http://www.R-project.org.

49. J. A. Sobrino and J. Cuenca, "Angular variation of thermal infrared emissivity for some natural surfaces from experimental measurements," Appl. Opt. 38(18), 3931-3936 (1999).

50. S. J. Hook et al., "Retrieval of lake bulk and skin temperatures using along-track scanning radiometer (atsr-2) data: a case study using Lake Tahoe, California," J. Atmos. Oceanic Technol. 20(4), 534-548 (2003).

Katharina Fricke is a researcher at the Federal Institute of Hydrology, Department GeoInformation and Remote Sensing, GRDC. She received her diploma in geography, environmental physics, and political sciences in 2008, and her PhD degree in geography in 2012 from Heidelberg University, Germany. Her current research interests include remote sensing, thermal infrared remote sensing, surface water temperature, atmospheric correction, spatial statistics, GIS, and geoinformatics. She is a member of SPIE.

Björn Baschek received his diploma in physics from Heidelberg University, Germany, in 2000. He received his PhD from the Swiss Federal Institute of Technology in Zurich (ETHZ) in radar remote sensing applied to meteorology. Since 2005, he has been working at the German Federal Institute of Hydrology (BfG) within the department Geo-Information and Remote Sensing (GRDC). His research interests include oil spill remote sensing and application of remote sensing for inland and coastal waters. He is a member of SPIE. 